\title{
Dinâmicas internacionais do agronegócio e implicações para a política agrícola brasileira
}

Gabriel da Silva Medina ${ }^{1}$

\section{Resumo}

Apesar da aposta brasileira na liberalização dos mercados agrícolas internacionais, mudanças recentes no cenário internacional devem ser consideradas pela política agrícola nacional. Este estudo revela os limites das negociações multilaterais para a redução dos subsídios agrícolas, a evolução das políticas agrícolas nacionais dos países desenvolvidos e emergentes e as tendências atuais de acordos bilaterais e plurilaterais entre grupos restritos de países, sem a participação brasileira. Essas dinâmicas atuais revelam que a política agrícola brasileira precisa evoluir do atual enfoque quase exclusivo ao crédito subsidiado em resposta a pressões imediatistas dos produtores rurais, para investimentos mais abrangentes que tragam maiores retornos em longo prazo para o setor rural como um todo. Investimentos em sistemas de informação, apoio institucional ao setor agropecuário e infraestrutura devem ser incorporados.

Palavras-chave: agronegócio, estratégia comercial, subsídios agrícolas.

JEL: 013

\begin{abstract}
Besides Brazil's commitment to the liberalization of international agricultural markets, recent changes in the international policymaking should be taken into account while reformulating the Brazilian agricultural policy. This study reveals the limits of multilateral negotiations for the reduction of agricultural subsidies worldwide, growing investments made in agricultural policies by both developed and emerging countries and current trends in bilateral and plurilateral trade agreements between small groups of countries, which exclude Brazil. Such developments reveal that the Brazilian agricultural policy needs to evolve from the current focus on shortterm subsidized credit responding to farmers' lobby, to sector-wide investments that in the longer run have a higher pay-off to the rural sector as a whole. Investments in knowledge systems, institutional support to the agricultural sector and infrastructure should be incorporated into the Brazilian agricultural policy.
\end{abstract}

Keywords: agribusiness, marketing strategy, agricultural subsidies.

1'Doutor em Ciências Naturais pela Universidade de Freiburg (Alemanha) (2008), Professor da Escola de Agronomia da Universidade Federal de Goiás (UFG) atuando nos cursos de graduação em ciências agrárias e no Programa de Pós-graduação em Agronegócio

Revista de Estudos Sociais | Ano 2017, N. 38, V. 19, Pag. 3 


\section{Introdução}

O direcionamento da política agrícola brasileira mantém a aposta na liberalização dos mercados agrícolas internacionais como base de sustentação do desenvolvimento nacional via exportação de commodities agropecuárias (MORAES, 2014). O argumento de fundo é que a redução do protecionismo pode aumentar o mercado internacional com benefícios mútuos para os países-membro da Organização Mundial do Comércio (OMC), como é o caso do Brasil (KHORANA et al., 2015). Essa abordagem tem dominado a política brasileira desde a década de 1990 quando o país deu início ao processo atual de abertura comercial (SAES; SILVEIRA, 2014).

A política agrícola brasileira tem ficado restrita ao atendimento das demandas mais imediatas apresentadas pelos produtores brasileiros e suas organizações representativas (CNA, 2015). A maior parte do crescente orçamento da política agrícola do país tem sido destinada a crédito subsidiado para produtores rurais, tanto no caso dos R $\$ 202$ bilhões do Plano Agrícola e Pecuário (PAP) 2016/17 voltado para grandes e médios produtores quanto dos $R \$ 30$ bilhões do Plano Safra 2016/17 voltado para agricultores familiares (MAPA, 2016; MDA, 2016). Como exemplo, o PAP 2016/17 trouxe investimentos de $\mathrm{R} \$ 168$ bilhões para crédito de custeio e de comercialização e $\mathrm{R} \$ 34$ bilhões para crédito de investimento (MAPA, 2016).

É limitado o esforço estratégico feito pela política agrícola brasileira para mapear as dinâmicas recentes do mercado internacional de produtos agrícolas e suas implicações para a agricultura nacional. Enquanto o enfoque praticamente exclusivo na política de crédito subsidiado beneficia os produtores rurais em curto prazo, no longo prazo, investimentos mais abrangentes como em sistemas de informação, apoio institucional e infraestrutura podem trazer maiores retornos para o setor rural como um todo (OECD-FAO, 2015; OLIVEIRA et al. 2015). O crédito subsidiado serve principalmente para compensar as baixas margens de lucro dos produtores brasileiros atuando em cadeias de mercado cada vez mais controladas por grupos multinacionais (MEDINA; RIBEIRO; BRASIL, 2016).

Estudos recentes têm mostrado os limites para a liberalização dos mercados agrícolas enfrentados pela Rodada de Doha da OMC (BELLMANN, 2014), assim como a manutenção das políticas agrícolas nos países desenvolvidos (MEDINA et al., 2015) e os crescentes investimentos feitos por países emergentes como China e Î́ndia (OECD, 2015). Nesse sentido, pode-se dizer que o investimento em políticas agrícolas é uma tendência internacional a despeito dos esforços de liberalização dos mercados, dada a importância estratégica da agricultura para a segurança alimentar e o desenvolvimento rural da maior parte dos países. Derivado desse cenário, têm sido crescentes os acordos bilaterais e plurilaterais de comércio entre grupos restritos de países como é o caso da Parceria Transpacífico (TPP) e da Parceria Transatlântica de Comércio e Investimento (TTIP) (AKHTAR; JONES, 
2013), embora o início do governo Donald Trump nos Estados Unidos sugira restrições ao TPP.

As dinâmicas internacionais têm implicações diretas no funcionamento dos mercados globais e para as exportações agropecuárias brasileiras e precisam ser consideradas pela política nacional na construção da estratégia de desenvolvimento do setor agropecuário (JOSLING et al., 2015). Estudos começam a evidenciar preocupações sobre a primarização da pauta brasileira de exportações em um cenário arriscado de concentração das vendas em poucas commodities para poucos mercados compradores, principalmente a China (AGUIAR; MATSUOKA, 2016). Diante desse cenário, é fundamental avaliar os limites da liberalização dos mercados agrícolas internacionais e suas implicações para a política agrícola brasileira. Baseado na revisão de literatura atual sobre o tema, este artigo busca especificamente:

- Identificar os resultados e limitações do esforço internacional para a liberalização multilateral dos mercados agrícolas levado a cabo principalmente pela OMC;

- Descrever a evolução das políticas agrícolas nacionais dos países desenvolvidos como União Europeia e Estados Unidos e emergentes como China e Índia;

- Avaliar as tendências atuais dos mercados agrícolas internacionais, incluindo acordos bilaterais e plurilaterais como o TPP e o TTIP;

- Concluir sobre as implicações dessas dinâmicas internacionais recentes para a política agrícola brasileira.

\section{Resultados da liberalização multilateral dos mercados agrícolas internacionais}

Na preparação para o Acordo sobre Agricultura (Agreement on Agriculture - AoA), que foi implementado a partir de 1995, os estados-membros da OMC se comprometeram com a liberalização dos mercados agrícolas (POTTER; TILZEY, 2007). As políticas nacionais tanto dos Estados Unidos quanto da Europa começaram a se afastar do uso de subsídios que distorcem mercado como políticas de garantia de preços ao produtor, que foram classificadas como de uso restrito (POTTER; TILZEY, 2007). Tanto Estados Unidos quanto Europa substituíram a política de preços por medidas que não distorcem o mercado como o pagamento direto, que foi classificado como de uso irrestrito (HUIGE et al., 2010). A redução dos subsídios que distorcem mercado foi uma das principais conquistas do G20 nas negociações, com papel protagonista exercido pelo Brasil (WADE, 2010).

Em dezembro de 2013 um acordo sobre um pequeno subconjunto de questões foi alcançado no chamado Pacote de Bali, que é o primeiro acordo verdadeiramente multilateral negociado sob os auspícios da OMC (BELLMANN, 2014). A peça central do pacote é um novo acordo sobre a facilitação do comércio com o objetivo 
de reduzir a burocracia e facilitar os procedimentos aduaneiros em um esforço para reduzir o custo das exportações. No entanto, além da facilitação do mercado, os avanços sobre agricultura, desenvolvimento e países menos desenvolvidos são limitados (BELLMANN, 2014; PALIT, 2015).

Um dos principais limites para o acordo em Bali foi colocado pelos países emergentes como a Índia. Pela necessidade de garantir a segurança alimentar da sua expressiva população rural, a Índia tem dificuldade de abrir mão da proteção da sua produção agrícola e das compras institucionais feitas pelo governo dos produtores rurais e de pequenos comerciantes locais (KHORANA et al., 2015). Essas características têm restringido a participação ampliada do país em acordos de livre comércio (KHORANA et al., 2015).

A dependência brasileira do mercado internacional é menor do que os outros BRIICS ou outras economias de tamanho comparável, em parte devido ao tamanho do mercado doméstico (OECD-FAO, 2015). No Brasil, o consumo interno absorve dois terços da produção agropecuária nacional, embora tenha havido maior crescimento da participação das exportações $(9,1 \%)$ do que do mercado interno $(3,8 \%)$ como destino da produção nacional nos últimos anos (Contini et al. 2012; Garcia and Vieira Filho 2014). A importância do mercado interno para o desenvolvimento nacional foi virou eixo estratégico da estratégia novodesenvolvimentista do governo federal brasileiro (MORAIS; SAAD-FILHO, 2011).

\section{Evolução das políticas agrícolas nacionais}

Dada à importância estratégica da agricultura, países desenvolvidos têm mantido suas políticas agrícolas e países em desenvolvimento as têm (re)estruturado. Agricultores de países desenvolvidos ligados à OECD ainda têm 17\% de sua renda garantida por transferências públicas (OECD 2015). Na União Europeia o valor é de $19 \%$ e nos Estados Unidos de $8 \%$ (OECD 2015), embora este último número suba para $37 \%$ se forem consideradas as transferências para o setor como um todo e não para os agricultores individualmente (European Parliament 2012). Embora esses países tenham restringido o uso de subsídios que distorcem mercado, seus investimentos em outros mecanismos de apoio têm sido crescentes (MEDINA et al., 2015).

A Política Agrícola Comum da União Europeia (PAC) tem concentrado seus esforços na complementação de renda do produtor rural pelo pagamento direto. Dos cerca de 57 bilhões de Euros ( $\mathrm{R} \$ 228$ bilhões) investidos anualmente na agricultura pela PAC, o pagamento direto é feito pelo primeiro pilar da política (que representa $74 \%$ do orçamento) atrelado ao cumprimento de normas específicas de cross-compliance e greening que têm caráter ambiental (EUROPEAN COMISSION, 2013). O orçamento do pagamento direto tem estado estável ao longo dos últimos anos, com leve crescimento entre o período de 2014-2020 e 2007-2013 (Tabela 1). Também foi estabelecido um segundo pilar (representando 
$23 \%$ do orçamento da política) que pode aumentar o repasse para o produtor pela adoção de Agri-environment Schemes (MEDINA et al., 2015).

Tabela 1. Evolução do orçamento da PAC e Farm Bill e de seus principais instrumentos de apoio direto aos agricultores

\begin{tabular}{|c|c|c|c|c|}
\hline & $\begin{array}{l}\text { PAC } \\
\text { (Total)* }\end{array}$ & $\begin{array}{l}\text { PAC } \\
\text { (Pagamento } \\
\text { direto)* }^{*}\end{array}$ & $\begin{array}{l}\text { Farm Bill } \\
\text { (Total) }{ }^{\star *}\end{array}$ & 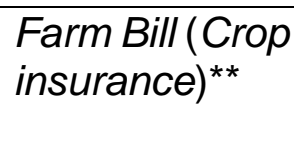 \\
\hline $\begin{array}{l}\text { Orçamento anual } \\
\text { médio para o período } \\
\text { anterior (2007-2013 na } \\
\text { PAC e 2008-2013 na } \\
\text { Farm Bill) (R\$ bilhões) }\end{array}$ & 208,0 & 165,6 & 198,8 & 25,8 \\
\hline $\begin{array}{l}\text { Orçamento anual } \\
\text { médio para o período } \\
\text { atual (2014-2020 na } \\
\text { PAC e 2014-18 na } \\
\text { Farm Bill) (R } \$ \text { bilhões) }\end{array}$ & 228,0 & 168,0 & 342,0 & 29,1 \\
\hline Crescimento (\%) & 9,6 & 1,4 & 72,0 & 11,2 \\
\hline
\end{tabular}

Fonte: *EUROPEAN PARLIAMENT, 2011; EUROPEAN COMISSION, 2013; ** JOHNSON; MONKE, 2014.

A Farm Bill americana abandonou recentemente o pagamento direto em favor do estabelecimento de uma rede de segurança (safety net) que protege o produtor em caso de perdas com produção ou preços dos produtos agrícolas. Respectivamente $8,5 \%$ e $4,8 \%$ dos 97,8 bilhões de dólares americanos ( $R \$ 342$ bilhões) investidos anualmente na agricultura vão para a proteção do produtor pelos programas Crop Insurance e Commodities Program (JOHNSON; MONKE, 2014). O orçamento do seguro agrícola (Crop Insurance) cresceu 11,2\% em relação à última Farm Bill (JOHNSON; MONKE, 2014). A maior parte do orçamento da política americana (80\%) vai para a compra de produtos destinados a alimentar pessoas em situação de insegurança alimentar, indiretamente favorecendo os produtores americanos pela criação de mercado institucional (JOHNSON; MONKE, 2014).

A China aumentou os investimentos em política agrícola para o equivalente a 3,2\% de seu PIB, e já subsidia cerca de 19\% da renda do produtor rural chinês (OECD, 2015). A estratégia chinesa passa pela busca de maior autonomia na produção interna de cereais e pelo controle de cadeias de comercialização de produtos estratégicos como soja produzidos na América do Sul e África. A Índia, que tem a segurança alimentar de sua população como enfoque estratégico, decidiu reforçar sua política agrícola para subsidiar a produção nacional e proteger o mercado interno (KHORANA et al., 2015). No Brasil, o principal esforço da política agrícola tem sido a crescente oferta de crédito subsidiado a produtores que hoje contam com $4 \%$ de sua renda atribuída às políticas agrícolas (OECD, 2015). Vale destacar 
que, dos cerca de $R \$ 232$ bilhões investidos anualmente pelo Brasil, cerca de 10\% são de recursos públicos destinados a subsidiar as taxas de juros das linhas de crédito e o restante do orçamento é de capital privado dos bancos (OECD, 2015).

Além dos subsídios internos e proteções alfandegárias, é importante destacar a adoção crescente de barreiras não tarifárias no mercado mundial, principalmente de barreiras sanitárias, em uma espécie de neoprotecionismo (LAMY; SOUZA JUNIOR, 2013). Apesar do esforço na OMC para garantir o uso legítimo das barreiras sanitárias, estudos têm revelado seu uso de forma recorrente em prejuízo das exportações brasileiras (BARBOSA da SILVA, 2013).

\section{Tendências atuais dos mercados agrícolas: acordos bilaterais e plurilaterais}

Com as limitações para avançar em um acordo multilateral de livre comércio pela OMC, que envolve 156 países-membros, acordos de caráter bilateral ou plurilateral envolvendo países selecionados com relações econômicas mais próximas ganharam protagonismo nas negociações internacionais. O acordo Transpacífico (TPP) acertado entre Estados Unidos, Japão, Chile, Peru e mais oito países reúne cerca de $40 \%$ da economia global. O acordo Transatlântico (TTIP) está sendo construído entre Estados Unidos e Europa e representaria 30\% das exportações mundiais (AKHTAR; JONES, 2013). Um terceiro acordo regional chamado Regional Comprehensive Economic Partnership (RCEP) está sendo negociado pela China, a associação dos países do Sudoeste da Ásia e países vizinhos (JOSLING et al., 2015).

A criação desses acordos tem impactos relevantes no Brasil e na América Latina como um todo pois pode provocar mudanças nas preferências comerciais estabelecidas (trade diversion and preference erosion) com grandes mercados importadores de commodities agrícolas (JOSLING et al., 2015). Como exemplo, as exportações do Brasil e Argentina para a Europa podem ser afetadas pela convergência de padrões aduaneiros entre EUA e União Europeia sendo construída no TTIP, que facilitariam as exportações americanas para a Europa.

Alternativas para região da América Latina e Caribe incluem: 1. A busca de maior integração regional partindo do longo histórico de acordos de livre existente na região (no caso brasileiro, com o Mercosul) e da aposta nos avanços da OMC para a busca de mercados externos; 2. A busca da maior integração com a América do Norte, incluindo a possibilidade de retomar as negociações sobre uma Área de Livre Comércio das Américas (Alca); 3. Aproximação com a União Europeia acreditando no sucesso do TTIP e; 4 . Integração com os países da Ásia, seja via aproximação com o RCEP, seja em acordos bilaterais com a China (JOSLING et al., 2015).

O Brasil é membro do Mercosul e tem investido esforços na sua expansão. Mas, pelo perfil de exportações agropecuárias brasileiras, com commodities produzidas em larga escala, o país tem concentrado suas exportações para fora da região, particularmente para a China que compra commodities em grande escala 
(JOSLING et al., 2015). Hoje a China é o principal destino da produção agropecuária brasileira respondendo por $23 \%$ do total de exportações (JOSLING et al., 2015). Produtos exportados como matéria prima representam $44 \%$ das exportações, com destaque para a soja que representa $26 \%$ das receitas as exportações de produtos agropecuários (AGUIAR; MATSUOKA, 2016; OECDFAO, 2015). O esforço brasileiro recente também inclui a negociação de um acordo de livre comércio com a União Europeia.

\section{Conclusão}

A despeito dos esforços para a liberalização dos mercados internacionais capitaneados pela OMC, dada a importância estratégica da agricultura, países desenvolvidos têm mantido suas políticas agrícolas e países em desenvolvimento as têm (re)estruturado. Possivelmente a Índia é o caso mais ilustrativo das dificuldades enfrentadas para a liberalização no setor agrícola sem colocar em risco a segurança alimentar de sua enorme população rural (KHORANA et al., 2015). A Rodada de Doha da OMC obteve avanços em seu esforço para a restrição de políticas agrícolas que distorcem mercados mas os limites dessa liberalização são muito evidentes, como ilustra o acordo alcançado em Bali em 2013 que não trouxe progressos na área agrícola (BELLMANN, 2014).

Com os limites das negociações multilaterais via OMC, alguns países tomaram a dianteira na promoção de acordos bilaterais e plurilaterais, como é o caso do TPP e do TTIP, envolvendo países selecionados com situações econômicas próximas e excluindo os países menos desenvolvidos (PALIT, 2015). Diante desse cenário, o Brasil encontra-se em uma encruzilhada com implicações geopolíticas relevantes pois pode buscar se associar aos Estados Unidos via TPP ou manter seu enfoque na China que tem sido seu principal parceiro comercial.

Diante desse cenário internacional dinâmico, a política agrícola brasileira precisa evoluir do atual enfoque quase exclusivo ao crédito subsidiado em resposta a pressões imediatistas dos produtores rurais organizados (CNA, 2015), para investimentos mais abrangentes podem trazer maiores retornos em longo prazo para o setor rural como um todo (OECD-FAO, 2015). Existe a necessidade de se considerar estrategicamente o mapeamento constante das dinâmicas do mercado internacional de produtos agropecuários e suas implicações para a agricultura nacional. A partir daí será possível construir estratégias assertivas de posicionamento brasileiro diante do novo cenário internacional. Investimentos em sistemas de informação e apoio institucional ao setor agropecuário devem ser incorporados à política agrícola brasileira.

Os ajustes na política agrícola brasileira devem partir de uma estratégia de longo prazo a ser construída para agronegócio nacional. Investimentos em produtos com maior valor agregado (como carnes) produzidos a partir de commodities agrícolas plantadas no país (como soja e milho) são importantes para reverter a primarização da pauta de exportações do Brasil (AGUIAR; MATSUOKA, 2016). O apoio a grupos 
nacionais estabelecidos ao longo das cadeias produtivas do agronegócio (dos produtores às tradings) é importante para aumentar a participação do capital brasileiro no agronegócio feito no Brasil, com maiores retornos financeiros para o país (MEDINA; RIBEIRO; BRASIL, 2016). Essas e outras ações estratégicas precisam ser apoiadas pela política agrícola brasileira que, para isso, precisa evoluir do atual enfoque quase exclusivo dado ao crédito subsidiado.

\section{Literatura}

AGUIAR, D; MATSUOKA, B. Mudanças na pauta de exportações e a primarização do complexo soja. Revista de Política Agrícola, 1(1): 20-34, 2016.

AKHTAR, S.; JONES, V. Proposed Transatlantic Trade and Investment Partnership (TTIP): In Brief. Congressional Research Service, 2013.

BARBOSA DA SILVA, L. Comércio Agrícola Internacional e as Barreiras do Acordo SPS da OMC. Revista de Política Agrícola, 4(4):25-37, 2013.

BELLMANN, C. The Bali Agreement: Implications for Development and the WTO." International Development Policy, 5(2), 2014.

CNA. Balanço 2015 Perspectivas 2016. Brasília: CNA, 2015.

CONTINI, E.; PENA JÚNIOR, M.; MARTHA JÚNIOR, G. Exportações: Motor do Agronegócio Brasileiro. Revista de Política Agrícola, 2(2):88-102, 2012.

EUROPEAN COMISSION. Overview of CAP Reform 2014-2020. European Comission, 2013.

EUROPEAN PARLIAMENT. Latest U.S. Farm Bill Developments. European Parliament, 2012.

EUROPEAN PARLIAMENT. The CAP in the EU budget: New objects and financial principles for the review of the agricultural budget after 2013. European Parliament, 2011.

GARCIA, J.; VIEIRA FILHO, J. Política Agrícola Brasileira: Produtividade, Inclusão e Sustentabilidade. Revista de Política Agrícola, 1(1):91-104, 2014.

HUIGE, R.; LAPPERRE, R.; STANTON, G. The WTO Context. Wageningen: Wageningen University, 2010

JOHNSON, R.; MONKE, J. What Is the Farm Bill? Congressional Research Service, 2014. 
JOSLING, T.; PAGGI, M.; WAINIO, J.; YAMAZAKI, F. Latin American Agriculture in a World of Trade Agreements. American Journal of Agricultural Economics, 97(2):546-67, 2015.

KHORANA, S.; PERDIKIS, N.; KERR, W. Global Economies of Scale in the EUIndia Trade Agreement: Are They the Key to a Return to Economic Growth? Asia Europe Journal, 13(1):41-55, 2015.

LAMY, A.; SOUZA JUNIOR, J. Internalização Do Acordo Sobre Aplicação de Medidas Sanitárias. Revista de Política Agrícola, 4(4):15-24, 2013.

MAPA. Plano Agrícola e Pecuário 2016/2017. Brasília: Ministério da Agricultura Pecuária e Abastecimento, 2016.

MDA. Plano Safra da Agricultura Familiar 2016-2017. Brasília: Ministério do Desenvolvimento Agrário, 2016.

MEDINA, G.; POTTER, C.; POKORNY, B. Farm Business Pathways under AgriEnvironmental Policies: Lessons for Policy Design. Estudos Sociedade e Agricultura, 23(1):5-30, 2015.

MEDINA, G.; RIBEIRO, G.; BRASIL, E. Participação brasileira na cadeia da soja: lições para o futuro do agronegócio nacional. Revista de Economia e Agronegócio, 13: no prelo, 2016.

MORAES, L. Brazil's Agricultural Policy Developments. Revista de Política Agrícola, 1(2):55-64, 2014.

MORAIS, L.; SAAD-FILHO, A. Da Economia Política à Política Econômica : O NovoDesenvolvimentismo E O Governo Lula. Revista de Economia Política, 31(124):507-27, 2014.

OLIVEIRA, M.; FERREIRA, R.; SIBALDELLI, S.; NASCIMENTO; JUNIOR, A. Análise Espacial da Produção da Soja e Capacidade Estática de Armazenamento no Estado do Mato Grosso. Revista de Estudos Sociais, 17(34):238-57, 2015.

OECD. Agricultural Policy Monitoring and Evaluation 2015. OECD, 2015.

OECD-FAO. OECD-FAO Agricultural Outlook 2015-2024. OECD/FAO, 2015.

PALIT, A. Mega-RTAs and LDCs: Trade Is Not for the Poor. Geoforum, 58:23-26, 2015

POTTER, C.; TILZEY, M. Agricultural Multifunctionality, Environmental Sustainability and the WTO: Resistance or Accommodation to the Neoliberal Project for Agriculture? Geoforum, 38(6):1290-1303, 2007. 
SAES, M.; SILVEIRA, R. Agropecuárias Brasileiras: Tendências Recentes. Estudos Sociedade e Agricultura, 22(2):386-407, 2014.

WADE, R. What Strategies Are Viable for Developing Countries Today? The World Trade Organization and the Shrinking of Development Space. Review of International Political Economy, 1(1):37-41, 2010. 